\title{
Hibernating Bears Conserve Muscle Strength and Maintain Fatigue Resistance
}

\author{
T. D. Lohuis ${ }^{1, *}$ \\ H. J. Harlow ${ }^{2}$ \\ T. D. I. Beck ${ }^{3}$ \\ P. A. Iaizzo ${ }^{4}$ \\ ${ }^{1}$ Alaska Department of Fish and Game, Soldotna, Alaska \\ 99669; ${ }^{2}$ Department of Zoology and Physiology, University of \\ Wyoming, Laramie, Wyoming 82071; ${ }^{3}$ Colorado Division of \\ Wildlife, 317 West Prospect Road, Fort Collins, Colorado \\ 80536; ${ }^{4}$ Department of Anesthesiology, University of \\ Minnesota, Minneapolis, Minnesota 55455
}

Accepted 1/25/2007; Electronically Published 2/9/2007

\section{ABSTRACT}

Black bears spend several months each winter confined to a small space within their den without food or water. In nonhibernating mammals, these conditions typically result in severe muscle atrophy, causing a loss of strength and endurance. However, an initial study indicated that bears appeared to conserve strength while denning. We conducted an in vivo, nonsubjective measurement of strength, resistance to fatigue, and contractile properties on the tibialis anterior muscle of six hibernating bears during both early and late winter using a rigid leg brace and foot force plate. After $110 \mathrm{~d}$ of anorexia and confinement, skeletal muscle strength loss in hibernating bears was about one-half that in humans confined to bed rest. Bears lost 29\% of muscle strength over $110 \mathrm{~d}$ of denning without food, while humans on a balanced diet but confined to bed for $90 \mathrm{~d}$ have been reported to lose $54 \%$ of their strength. Additionally, muscle contractile properties, including contraction time, halfrelaxation time, half-maximum value time, peak rate of development and decay, time to peak force development, and time to peak force decay did not change, indicating that no small-scale alterations in whole-muscle function occurred over the winter. This study further supports our previous findings that black bears have a high resistance to atrophy despite being subjected to long-term anorexia and limited mobility.

\footnotetext{
* Corresponding author. Address for correspondence: Alaska Department of Fish and Game, Kenai Moose Research Center, 43961 Kalifornsky Beach Road, Suite B, Soldotna, Alaska 99669; e-mail: thomas_lohuis@fishgame.state.ak.us.
}

Physiological and Biochemical Zoology 80(3):257-269. 2007. (C) 2007 by The University of Chicago. All rights reserved. 1522-2152/2007/8003-5202\$15.00

\section{Introduction}

The black bear (Ursus americanus) spends 4-7 mo each winter hibernating in its den (Beck 1991). Bears do not arouse during the winter to eliminate metabolic waste or eat and drink during hibernation (Nelson et al. 1973, 1983; Harlow et al. 2004), but they are capable of initiating a profound locomotor response to a threat or disturbance even while in a state of mild hypothermia. Indeed, bears demonstrate unimpaired locomotor function during the winter and are able to sustain walking and running through heavy snow without noticeable strength loss or fatigue (T. D. I. Beck, personal observation of several hundred denned bears). The apparent retention of locomotor function is remarkable considering that the bear is confined to a small space with limited mobility, has no access to food or water, and maintains a body temperature that is only a few degrees below its activity range for an entire winter (Nelson et al. 1973; Harlow et al. 2004). These observations prompted our studies on overwintering bears with a focus on comparison with traditional models of skeletal disuse atrophy and with studies on smaller vertebrate species that either hibernate or estivate.

There is a large body of literature quantifying muscle disuse atrophy on four model systems: microgravity (Edgerton et al. 1995; Lambertz et al. 2000; LeBlanc et al. 2000), bed rest (Dudley et al. 1989; LeBlanc et al. 1992; Berg et al. 1997; Widrick et al. 1998; Alkner and Tesch 2004), limb immobilization by casting (Hortobagyi et al. 2000; Thom et al. 2001; Krawiec et al. 2005) or by suspension (Berg et al. 1991; Ploutz-Snyder et al. 1996), and denervation with spinalization or spinal isolation (Talmadge et al. 1995, 1999; Haddad et al. 2003). The response is similar for all models and is predominantly described in rats, mice, and humans (reviewed in Baldwin and Haddad 2001; Adams et al. 2003).

Uniformly, all atrophy models show a profound decrease in myofibrillar and sarcoplasmic protein (Larsson et al. 1996; Berg et al. 1997; Gamrin et al. 1998; Lecker et al. 1999; reviewed in Lecker and Goldberg 2002) and whole-muscle cross-sectional area and mass (LeBlanc et al. 1992; Narici et al. 1997; Krawiec et al. 2005; reviewed in Adams et al. 2003) as well as fiber size (Edgerton et al. 1995; Hortobagyi et al. 2000; Rittweger et al. 2005). Atrophy models are also characterized by a loss of skeletal muscle strength (Dudley et al.1989; Hortobagyi et al. 2000; 
Roy et al. 2002; reviewed in Adams et al. 2003) and reduced aerobic capacity and resistance to fatigue (McDonald et al. 1992; Zhan and Sieck 1992). In addition, under some conditions, the time course of in vivo muscle contractile properties may be altered as a result of changed myosin heavy chain (MHC) isoforms (reviewed in Baldwin and Haddad 2001; Caiozzo 2002) or changed sarcoplasmic reticulum calcium kinetics (Schulte et al. 1993) in response to unloading.

Skeletal muscle of adult mammals is polymorphic. Muscle fibers generally referred to as slow-twitch oxidative predominantly contain the slow type I MHC isoforms, while fast-twitch glycolytic fibers contain greater, yet variable, amounts of the faster IIa, IIx, or IIb MHC isoforms (reviewed in Caiozzo 2002). The relative expression of these MHC isoforms in the muscle is subject to resculpturing as a result of atrophy (reviewed in Baldwin and Haddad 2001). In most animal models, skeletal muscle atrophy affects predominantly slow-twitch oxidative rather than fast-twitch glycolytic fibers, though human models do not appear to show the same characteristic response (Thomason and Booth 1990; Fitts et al. 2000, 2001; Haddad et al. 2003; Alkner and Tesch 2004). This atrophy is associated with a loss of type I MHC slow isoform composition of skeletal muscle (reviewed in Baldwin and Haddad 2001). Changes in MHC composition have complex effects on muscle function (reviewed in Caiozzo 2002), but some researchers report that atrophy models, including unloading, spaceflight, immobilization, limb suspension, and denervation, may result in partial or complete conversion of slow to fast fibers or slow to fast MHC transformations (Desplanches et al. 1987; Andersen et al. 1999; reviewed in Baldwin and Haddad 2001). Because the isoform composition of a muscle influences the force-velocity relationship and therefore the amount and time course of power output from a muscle (reviewed in Caiozzo 2002; Adams et al. 2003), it follows that atrophy can result in altered whole-muscle contractile parameters (Caiozzo et al. 1998; Haddad et al. 2003). These include contraction time, half-relaxation time, and associated measurements that evaluate the time course of muscle movement. Indeed, alterations in some of these parameters have been shown to accompany functional decrements as a result of unloading or immobilization even in cases where largescale atrophy or complete fiber type conversion may not be observed (Larsson et al. 1996; Hortobagyi et al. 2000; reviewed in Caiozzo 2002). Thus, changes in contractile properties could serve as further indicators of compromised whole-muscle function.

The skeletal muscle of hibernating mammals may not express many of the above effects. Previous studies have suggested that hibernating small mammals, such as prairie dogs (Harlow and Menkens 1985; Cotton 2005), hamsters (Wickler et al. 1987), ground squirrels (Steffen et al. 1991; Wickler et al. 1991; Reid et al. 1995; Rourke et al. 2004a, 2004b), and bats (Yacoe 1983), either suffer limited losses of muscle size, protein, strength, and muscle fiber integrity compared to atrophy in nonhibernators or are protected from such losses. Estivating amphibians have also been found to exhibit protein sparing and maintenance of muscle integrity during winter (Hudson and Franklin 2002a, 2002b; Layne and Rice 2003; Hudson et al. 2006; West et al. 2006), which may be due in part to cellular mechanisms in concert with very low body temperatures (Hudson and Franklin 2002a).

In contrast to hibernating bears, which exhibit mild hypothermia of only $2^{\circ}-5^{\circ} \mathrm{C}$ below normal and do not arouse unless disturbed (Nelson et al. 1973; Harlow et al. 2004), smallmammal hibernators decrease their body temperature $30^{\circ}-35^{\circ} \mathrm{C}$ below normothermia but arouse every $1-3$ wk to urinate, defecate, and even drink water, depending on the species (Harlow and Menkens 1985; Barnes 1989; Boyer and Barnes 1999). Gluconeogenic demands associated with repeated arousal from multiple torpor bouts necessitate protein catabolism (Burlington and Klain 1967; Galster and Morrison 1975), which may account for measurable losses of muscle protein in some smallmammal hibernators (Yacoe 1983; Steffen et al. 1991; Wickler et al. 1991) but not in others (Cotton 2005). However, while repeated arousal bouts may require protein catabolism, it is believed that they may also be important to facilitate the maintenance of skeletal muscle integrity as a result of vigorous shivering episodes (Rourke et al. 2004a, 2004b). Also unlike smallmammal hibernators, bears appear to exhibit nitrogen balance throughout the winter (Koebel et al. 1991; Barboza et al. 1997; Tinker et al. 1998; Lohuis et al. 2007) and may exhibit subtle muscular activity that does not result in complete arousal (Harlow et al. 2004) and therefore would not require substantial protein catabolism. The combination of relatively unaltered muscle structure (Tinker et al. 1998), nitrogen balance (Barboza et al. 1997; Lohuis et al. 2007), and the lack of the repeated arousals experienced by small-mammal hibernators (Harlow et al. 2004) may result in greater strength retention by bears than expressed by traditional disuse atrophy models and similar or greater strength retention by bears than by small-mammal deep-hibernating species exposed to prolonged periods of reduced activity and food intake. Indeed, our initial study (Harlow et al. 2001) demonstrated a lower percentage loss of skeletal muscle force by overwintering bears than predicted by human or other animal models of muscle atrophy.

The objectives of this study are to measure muscle strength, contractile characteristics, and resistance to fatigue nonsubjectively in vivo on naturally denning black bears during early and late winter. We address three questions: (1) How do muscle strength and associated contractile characteristics change between early and late hibernation? (2) Do skeletal muscles of bears maintain fatigue resistance, indicative of slow oxidative fiber retention, between early and late hibernation? (3) How does the bear compare to traditional disuse atrophy models and to small vertebrate species engaged in deep hypothermia? Data from this study will help us to understand the extent of strength retention in hibernating bears and to draw a closer 
association between fiber morphology, contractile properties, and fatigue resistance of an animal exposed to prolonged periods of dramatically reduced activity and food intake while in a state of mild torpor.

\section{Material and Methods}

\section{Bear Capture and Handling}

Six adult (five female, one male) bears were captured in Middle Park, Colorado $\left(40^{\circ} 05^{\prime} \mathrm{N}, 105^{\circ} 59^{\prime} \mathrm{W} ; 2,580-3,550\right.$ m elevation) during the summer in $1 \times 1 \times 2$-m woven metal box traps with a spring door activated by a foot treadle. Bears were anesthetized with tiletamine-zolezapam (Telazol; $7.0 \mathrm{mg} / \mathrm{kg}$ ) administered with a $1-\mathrm{m}$ spring-operated jab pole. They were then placed on a Therm-a-Rest pad, and their body temperature was continuously monitored rectally with a digital thermometer. Radio telemetry collars (ATS, Isanti, MN) transmitting in the $150-152-\mathrm{MHz}$ range were placed around the neck of each animal.

Bears were located in their winter dens using aerial and ground telemetry and tested within approximately $2 \mathrm{wk}$ of the initiation of their hibernation season (median sampling date $=$ November 28). Four of these bears were also tested again in late winter before emergence from the den (median sampling date $=$ March 15). The mean interval between den visits was $110 \mathrm{~d}$. Of the original six bears sampled in early winter, two left their dens and could not be located. Thus, we substituted two bears (one male, one female) that had not been sampled but were of similar age and body mass as the original two lost bears. These bears responded to all tested parameters similarly to the four sequentially sampled animals and were included as a part of the late-winter group.

Bears were anesthetized in their den during early and late winter using the same protocol described for summer animals. After removal from the den, bears were placed on a Therm-aRest pad, covered with a blanket to prevent abnormal hypothermia, and fitted with a leg brace and force plate for muscle strength and fatigue assessment as described below.

After sampling, bears were placed back into their den, and the entrance was covered with pine boughs and snow to encourage them to remain in their original den sites. All handling and experimental procedures were approved by the Colorado Division of Wildlife and University of Wyoming animal care and use committees.

\section{In Vivo Strength and Fatigue Assessment}

The method for assessing strength and fatigue of an intact muscle of a bear used in this study is an adaptation of a system used for the evaluation of neuromuscular disease progression in humans (Brass et al. 1996; Schulte-Mattler et al. 2003). The apparatus consisted of an aluminum leg brace that held the lower hindlimb of the anesthetized bear in a defined, repeatable po- sition, with the foot firmly secured against a platform and a Wheatstone bridge force transducer (Fig. 1). Internal motion that could dampen the signal was eliminated by application of pressure to the top of the knee. The knee, leg, and foot were then secured to the apparatus with $2.5-\mathrm{cm}$ nylon straps. Supramaximal electrical stimulation of the common peroneal nerve caused dorsiflexion of the tibialis anterior, resulting in force reading from the foot platform. The system was controlled by a Compaq Armada 1575DM laptop computer with the Labview 5.0 program used for stimulus generation and data acquisition. Labview 5.0 calculated force output according to the following equation: force in newton-meters $=(5.211 \times$ volts $) / 0.17$. This equation was derived by using a series of known masses hung from a lever arm to depress the foot pedal, recording the voltage output, and then generating a standard curve of voltage output as a function of torque calculated for each mass at the known distance of the lever arm. Electrical stimulation and signal amplification were provided by custom-built hardware (University of Wyoming Division of Research Support, machine and electrical shops). A constant current stimulus (range 100-300 V) was delivered by a pair of $8.5-\mathrm{mm}$-diameter silver disk electrodes placed $3 \mathrm{~cm}$ apart (Nicolet Biomedical, Madison, WI; Fig. 1). Power was provided by two $12-\mathrm{V}$ deep-cycle gel-cell batteries with a $12-\mathrm{V} \mathrm{DC}$ AC power converter.

An area of approximately $6 \mathrm{~cm} \times 6 \mathrm{~cm}$ was shaved over the fibular head, allowing electrical stimulation of the common peroneal nerve, and the bear's lower hindlimb was placed in the brace. Estimated supramaximal electrical stimuli were delivered, and strength output was monitored while the ankle joint was rotated in the brace in order to locate the optimal length-tension relationship of the fibers in the tibialis anterior. The optimal length-tension position is achieved when the foot is positioned so that actin and myosin filaments in the muscle maximally overlap and provide the greatest possible force production. The aluminum leg brace allowed rotation of the foot around the ankle joint to stretch the tibialis anterior and was marked in $10^{\circ}$ increments to allow consistent, repeatable positioning. We established the optimal length-tension relationship by first increasing stimulus intensity until the measured force production no longer increased, ensuring that a supramaximal stimulus had been reached. At no time was the maximum possible stimulus voltage required to elicit a supramaximal stimulus. Typically, as defined above, a supramaximal stimulus was attained at between $60 \%$ and $80 \%$ of the maximum possible stimulus voltage. Then, the ankle joint was rotated in $10^{\circ}$ increments to determine which position generated the strongest contraction, representing the optimal lengthtension position. After the tibialis anterior was positioned, stimulus intensity was again increased to ensure activation of all fibers in the muscle. The ankle was then returned to a neutral position, and the stimulus intensity was lowered. This process was repeated in triplicate before data collection to ensure repeatable, nonsubjective determination of optimal length and 


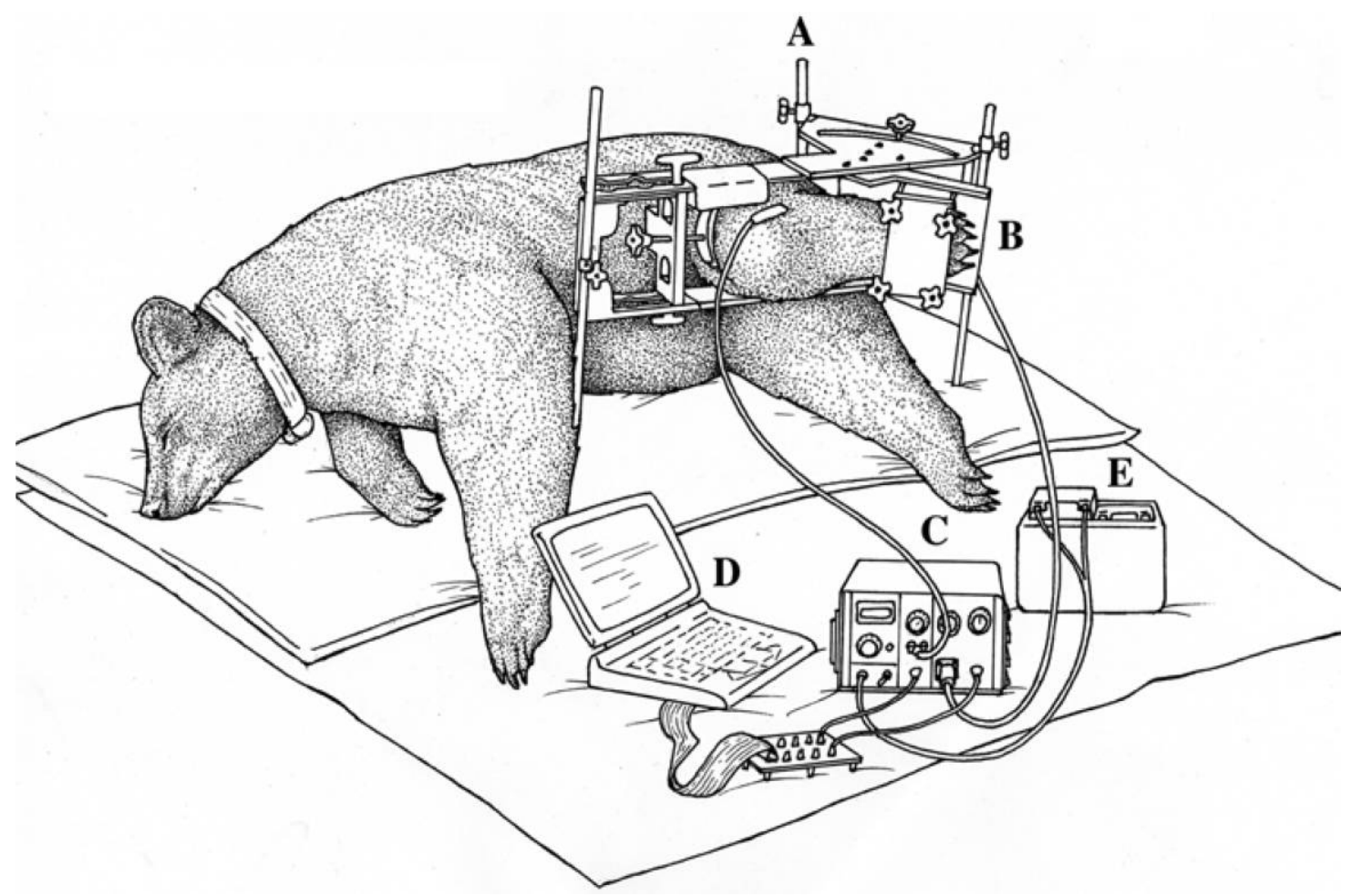

Figure 1. In vivo strength and fatigue assessment apparatus. The aluminum leg brace $(A)$ is designed to provide consistent, repeatable positioning of the lower hindlimb. Strength and fatigue are measured by the foot plate and Wheatstone bridge strain gauge $(B)$. Single-pulse stimuli for strength assessment and trains of stimuli at $0.2,0.5,1.0,3.0$, and $5.0 \mathrm{~Hz}$ for fatigue assessment are delivered by a custom-built stimulator $(C)$. Stimulus generation and data collection are controlled by a Compaq laptop computer $(D)$. Power is supplied by a 12 -V deep-cycle gel-cell battery $(E)$. Figure reprinted with permission from Harlow et al. (2001).

stimulus intensity. Both the stimulus intensity and ankle position necessary to generate a supramaximal stimulus were recorded in all bears tested. In all animals that were repeatedly tested, optimal ankle positions were identical between early and late hibernation.

Muscle force, in addition to six other parameters describing muscle function and fiber composition, were calculated and recorded by the Labview program each time a contraction was generated. Parameters were defined according to Brass et al. (1996) and included contraction time (the interval between the onset of force and the time of peak force), half-relaxation time (the time from peak force development to the time at which force decays to one-half of peak force), rate of peak force development and rate of peak decay (the maximum rate of force development and decay), time to peak decay (the time interval between the peak rate of development and the peak rate of decay), and the half-maximum value time (the time when the generated force is maintained at a level of one-half or greater of the peak force).

Supramaximal stimuli were given $1 \mathrm{~min}$ apart with the ankle secured to measure maximum muscle force. Mean values of three such contractions were compared between early- and latewinter sampling seasons.

Core body temperature was continuously monitored during testing procedures with an Atkins model 396K thermocouple thermometer (Gainesville, FL), with a lubricated $0.5-\mathrm{cm}$ blunt probe inserted $7 \mathrm{~cm}$ into the rectum. Tibialis anterior temperature was measured with the same device but using a sterile 18 -ga needle probe inserted $2 \mathrm{~cm}$ into the muscle at the conclusion of the strength testing procedure. Mean late-winter core body and extremity temperatures were both $1.3^{\circ} \mathrm{C}$ lower compared with early-winter temperatures, while extremity temperatures averaged $2.4^{\circ} \mathrm{C}$ colder than core temperatures in both early and late winter. Force generated by mammalian muscle has been shown to decrease with temperature (Buller et al. 1984; Iaizzo and Poppele 1990). Therefore, at the conclusion of latewinter strength and fatigue measurements, we applied chemical heat packs to the tibialis muscle and recorded muscle force values in response to the same test stimuli used to assess strength at progressively increasing muscle temperatures ranging from $29.2^{\circ}$ to $34.6^{\circ} \mathrm{C}$. Strength was measured between four and seven times at different temperatures on each bear tested. 
Using these data, we calculated a temperature coefficient $\left(\mathrm{Q}_{10}\right)$ factor of 3.3, which was then used to standardize all force values and contractile properties to a stereotypical muscle temperature of $34^{\circ} \mathrm{C}$, the mean extremity temperature measured in the earlywinter-hibernating bears. While $\mathrm{Q}_{10}$ coefficient correction factors for muscle contraction strength become nonlinear at extreme temperatures, we never measured a muscle temperature lower than $29^{\circ}$ or warmer than $36^{\circ} \mathrm{C}$ in these bears. Therefore, we assumed that within the range of temperatures we measured in these bears, $Q_{10}$ correction factors were linear (De Ruiter and De Haan 2000; Hilber et al. 2001; Wang and Kawai 2001)

Muscle fatigue was measured using a $15-\mathrm{min}$ protocol previously employed on humans (Schulte-Mattler et al. 2003). The protocol alternated $1 \mathrm{~min}$ of stimulation beginning at $0.5 \mathrm{~Hz}$ with 2 min of rest. Stimulus frequency was increased after every 2-min rest interval, so that there were five 1-min periods of repeated supramaximal stimuli delivered at 0.5, 1.0, 2.0, 3.0, and $5.0 \mathrm{~Hz}$. Choice of this stimulus protocol was due to experimental goals. In order to compare the response of denned bears to decreased mobility and anorexia with the response of human clinical patients, we needed to use a protocol similar to one employed on humans. Stimulus rates greater than $5 \mathrm{~Hz}$ are not well tolerated by awake human patients. In addition, stimulus frequencies greater than $5 \mathrm{~Hz}$ can generate tetanic potentiation (Schulte-Mattler et al. 2003). We did not observe potentiation at any stimulus frequency presented.

Data were then used to calculate a fatigue index, the difference in force output between the mean of the first 10 and mean of the last 10 stimuli of a stimulus interval, expressed as a percentage (Haida et al. 1989; Zhan and Sieck 1992; Reid et al. 1993; Schulte-Mattler et al. 2003). The fatigue index at each stimulus frequency was compared between early- and latewinter animals.

\section{Statistical Analysis}

Paired $t$-tests were performed using Sigmastat (Systat, Point Richmond, CA) to assess significant differences in the mean values of the measured parameter between seasons on the four animals that were measured in both early and late denning (Zar 1999). Alpha levels were set at 0.05. Because two of the initial six bears left the study area after early-winter sampling, two additional bears of the same size and age class were located and sampled in their dens during late-winter hibernation to increase sample size. Additionally, Student's $t$-tests were performed using Sigmastat to assess significant differences in the mean values of the measured parameter between the initial six (early-winter cohort) bears and the final six (late-winter cohort) to include the two substitutes (Zar 1999). Alpha levels were again set at 0.05 . All of the significant differences we detected between early- and late-winter muscle performance were identical $(P<0.05)$ using either the paired $t$-test on four bears or the Student's $t$-test on six bears. All results are presented here as the mean $( \pm S E)$ of six bears.

Fatigue indices were normalized so that the initial twitch force in a train represented a maximal value expressed as $100 \%$, which then declined over time as a result of muscle fatigue. Data expressed as percentages were then arcsine transformed. Data expressed as percentages tend to be distributed binomially rather than normally. Arcsine transformation ensures normal distribution (Zar 1999, p. 239). Differences were then tested with a paired $t$-test (four bears that were studied in both early and late winter) and a Student's $t$-test (entire cohort of six early-winter and six late-winter bears, including two substitutes). All results are again presented as the mean $( \pm S E)$ of six bears.

\section{Results}

\section{Skeletal Muscle Strength and Contractile Properties}

Muscle strength measured in vivo based on maximum twitch force in the tibialis anterior of denning bears was 29\% greater (Fig. 2) in bears in early hibernation (24.08 \pm 4.4 newtonmeters) than in bears in late hibernation (17.11 \pm 2.33 newtonmeters; $P=0.04)$. Figure 3 compares single muscle twitches from a representative bear (844) in both early (November) and late (March) hibernation. Seven contractile parameters indicative of muscle fiber type composition were also measured in the course of this study. Contraction time, half-relaxation time, half-maximum value time, peak rates of development and decay, and time to peak force development and decay were not significantly different $(P>0.05)$ between early and late hibernation (Table 1).

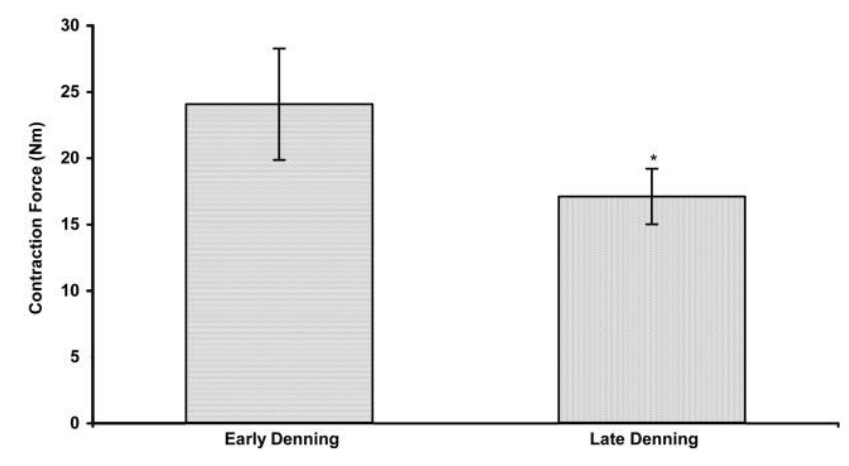

Figure 2. Skeletal muscle strength, measured in vivo over a $110-d$ interval of denning inactivity and anorexia. Vertical bars show the mean force output in newton-meters by the tibialis anterior of six bears in response to a multiple-pulse stimulus to the peroneal nerve. Vertical lines represent \pm 1 SEM. Asterisk indicates significant $(P<0.05)$ decrease in strength between early-winter (left bar) and late-winter (right bar) bears. 


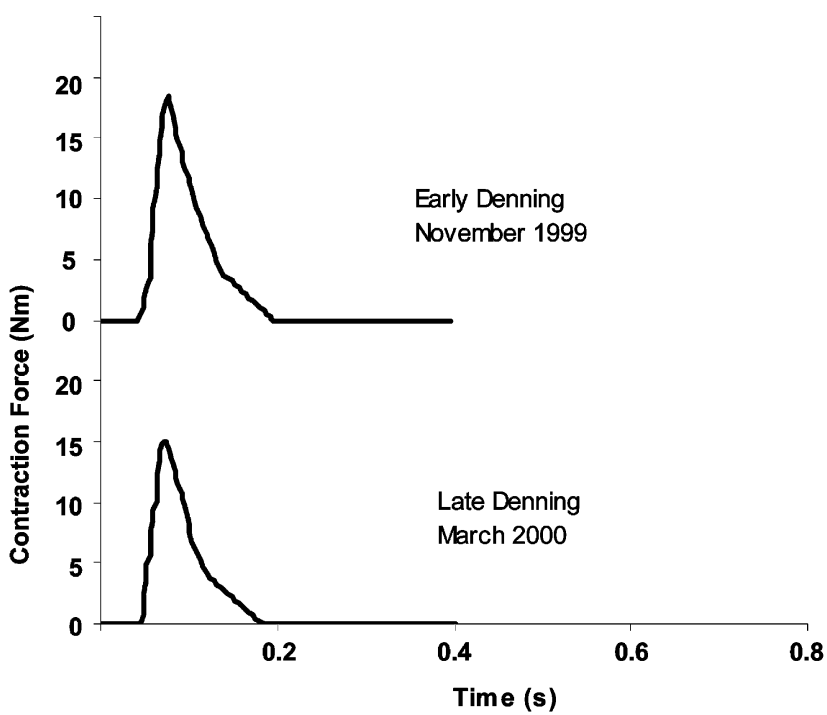

Figure 3. Representative muscle twitch recordings from the tibialis anterior muscle. Upper trace was recorded during early denning (November); lower trace was recorded during late denning (March).

\section{Skeletal Muscle Fatigue}

Bears in late hibernation were more susceptible to fatigue than were bears in early hibernation. Stimulation at $0.5,1.0$, and 2.0 $\mathrm{Hz}$ did not cause measurable fatigue in tibialis anterior of either early- or late-winter-hibernating bears. For all bears tested, 3$\mathrm{Hz}$ stimulation caused a decrease in force output by the tibialis anterior over $1 \mathrm{~min}$ of stimulation in late-winter-hibernating bears (initial force normalized to $100 \%$, force after $1 \mathrm{~min}=$ $71.29 \%, P=0.011$ ) but not in early-winter-hibernating bears (initial force normalized to $100 \%$, force after $1 \mathrm{~min}$ of $3-\mathrm{Hz}$ stimulation $=99.8 \%, P=0.17)$. Stimulation at $5 \mathrm{~Hz}$ also caused a greater decrease in force output, and therefore greater fatigue, by the tibialis anterior in late-winter-hibernating bears (initial force normalized to $100 \%$, force after $1 \mathrm{~min}=$ $54.34 \%, P=0.019$ ) than in early-winter-hibernating bears (initial force normalized to $100 \%$, force after $1 \mathrm{~min}=85.68 \%$, $P=0.018$; Fig. 4). Figure 5 is an example of evoked twitches at 2-, 3-, and 5- $\mathrm{Hz}$ stimulation from bear 804 in early (November) and late (March) hibernation. Stimulation at $5 \mathrm{~Hz}$ produced a greater fatigue response than did stimulation at 3 $\mathrm{Hz}$, while stimulation at $2 \mathrm{~Hz}$ was not sufficient to induce fatigue in either early or late hibernation.

\section{Discussion}

Fasting (Knapik et al. 1987; Koerts-DeLang et al. 1998), unweighting (Adams et al. 2003; Haddad et al. 2003), or immobility (Hortobagyi et al. 2000; Ferretti et al. 2001) results in compromised muscle function resulting from the loss of muscle contractile protein. Because bears are confined and anorexic for several months during winter but can still retain muscle protein (Tinker et al. 1998) and display sustained activity if disturbed, we measured skeletal muscle strength, fatigue resistance, and in vivo contractile properties of intact muscle in bears within their natural dens.

We reported in an earlier study (Harlow et al. 2001) that black bears appeared to conserve skeletal muscle strength during hibernation. In that article, however, we were unable to provide information on muscle contractile properties, muscle temperature, and endurance to increase understanding of muscle performance. Here, we present results on those contractile properties and muscle fatigue while adjusting measurements of muscle strength output for temperature.

\section{In Vivo Measurement of Skeletal Muscle Strength}

Peak force production, adjusted for temperature, by bear tibialis anterior muscle in this study decreased by $29 \%$ over about 110 $\mathrm{d}$ of confinement while without food or water. This value is similar to that in our earlier study showing a loss of $23 \%$ in force production by a different cohort of overwintering bears (Harlow et al. 2001). For comparison, in humans confined to bed rest for $90 \mathrm{~d}$, peak force production, measured as the maximum voluntary contraction generated by plantar flexor muscles, decreased by $54 \%$ of pretrial levels, while peak force production from knee extensors decreased by 51\%-60\% (Alkner and Tesch 2004). These values are of similar magnitude to the findings of Koryak (1998), a loss of $45 \%$ by triceps surae. Studies on immobilized humans show a similar magnitude of loss over a shorter time course. For example, Hortobagyi et al. (2000) report a $47 \%$ decline in strength after only $3 \mathrm{wk}$ of knee immobilization by casting. Spinal isolation results in a $33 \%$ drop in strength after $60 \mathrm{~d}$ (Roy et al. 2002). Spaceflight (Tesch et al. 2004) induces a 9\%-11\% decrease in maximum voluntary force production by knee extensor muscles after an extremely short (relative to the length of the current study) 17-d spaceflight, despite exercise sessions throughout the duration of the flight. While the progression of atrophy and accompanying strength loss is not linear over the time course of immobilization or bed rest and appears to proceed at a greater rate at the onset of immobilization than later (Thomason and Booth 1990; LeBlanc et al. 1992; Haddad et al. 2003; Alkner and Tesch 2004), Tesch et al. (2004) report that this magnitude of strength loss (9\%-11\% in 17 -d spaceflight) is similar to that experienced by other human models, and it is therefore to be expected that longer-duration spaceflight would have an effect similar to those found in long-term bed rest studies such as those conducted by Alkner and Tesch (2004) and Koryak (1998). Indeed, reports of strength loss from several muscle groups during longer-duration spaceflights extend up to $48 \%$ over a 90-180d period (Greenleaf et al. 1989; Zange et al. 1997; Lambertz et al. 2000).

Further, the magnitude of strength loss by human experi- 
Table 1: Twitch parameters of tibialis anterior during early- and late-

denning seasons

\begin{tabular}{lcc}
\hline & Early Denning & Late Denning \\
\hline Contraction time $(\mathrm{ms})$ & $41.9(1.39)$ & $41.7(1.9)$ \\
Half-relaxation time $(\mathrm{ms})$ & $74.4(9.5)$ & $95.0(14.9)$ \\
Peak rate of development $(\mathrm{Nm} / \mathrm{ms})$ & $84.77(37.18)$ & $84.14(30.13)$ \\
Peak rate of decay $(\mathrm{Nm} / \mathrm{ms})$ & $-47.83(13.48)$ & $-48.1(11.24)$ \\
Time to peak development $(\mathrm{ms})$ & $46.7(16.9)$ & $44.7(16.2)$ \\
Time to peak decay $(\mathrm{ms})$ & $28.1(6.5)$ & $25.8(4.1)$ \\
Half-maximum value time $(\mathrm{ms})$ & $18.8(8.4)$ & $12.8(7.9)$ \\
\hline
\end{tabular}

Note. Values are given as means with SEM in parentheses. $\mathrm{Nm}=$ newton-meter.

mental subjects may be greater than reported because of the subjectivity of the monitoring protocol. For example, strength is generally assessed in humans by measuring force generated through voluntary contractions (Gogia et al. 1988; LeBlanc et al. 1992; Berg et al. 1997) rather than force evoked by an established supramaximal stimulus at an optimal length-tension relationship as employed in this study. In addition, other factors such as nutrition and energy intake can influence strength. For example, fasting compounds the effect of immobility in humans and has been shown to profoundly reduce strength expression of skeletal muscles. Specifically, Knapik et al. (1987) documented a $10 \%$ decrease in isokinetic strength of elbow flexors after only $3.5 \mathrm{~d}$ of fasting. Black bears are completely fasted during the winter, and even though they do not undergo weightlessness, casting, or denervation, they do experience limited mobility. Their strength loss during this time is markedly lower than that of animal models subjected to only a single perturbation, much less a combination of food deprivation and immobility that induces muscle atrophy.

Despite the bears' ability to preserve skeletal muscle and maintain muscle strength and function over $110 \mathrm{~d}$ of denningimposed anorexia and inactivity, the protein sparing effect is not complete. Metabolic demands for gluconeogenic precursors and tricarboxylic acid cycle intermediates necessitate a moderate amount of protein catabolism (Bintz et al. 1979; Yacoe 1983). However, Barboza et al. (1997) proposed that small losses of protein from several muscle groups would be sufficient to meet the denning bears' metabolic demands for protein without severely compromising muscle function. Both Koebel et al. (1991) and Barboza et al. (1997) estimated that a total loss of body protein of approximately $10 \%$ would occur during winter dormancy. This supposition was confirmed by Harlow et al. (2002), who reported losses of $7.6 \%$ of total body protein in overwintering, nonreproductive bears.

Interestingly, if we use the estimation of Hortobagyi et al. (2000) that strength loss is approximately four times greater than protein loss, the $29 \%$ reduction in strength reported here translates to a $7.25 \%$ loss of protein content in the tibialis anterior over the $110 \mathrm{~d}$ of denning anorexia and inactivity. This estimation is similar to the measurements of protein loss in gastrocnemius (loss of $4 \%-10 \%$ of muscle protein), biceps femoris (10\%), and extensor hallucis longus (10\%) by overwintering bears reported by Tinker et al. (1998) and Koebel et al. (1991). These muscles represent both hindlimb flexors and extensors and, in combination with the tibialis anterior (this study), provide evidence for limited protein loss in black bear hindlimb muscles during hibernation.

In a companion study on biopsies from the vastus lateralis, a knee extensor muscle, no significant loss of protein or loss of strength, measured in vitro (Lohuis 2002; Lohuis et al. 2007), was observed over the same hibernation interval. It is well documented that protein loss, as a result of either limited mobility or fasting, varies between muscle groups (Li and Goldberg 1976; Gogia et al. 1988; LeBlanc et al. 1992). In addition, penguins (Cherel et al. 1994), geese (LeMaho et al. 1981), bats (Yacoe 1983), and ground squirrels (Steffen et al. 1991; Wickler et al. 1991), all species that are adapted to endure long-term fasting, appear to catabolize protein from certain skeletal muscles while preserving protein, mass, and function in others. It is apparent that the hibernating black bear has developed a similar strategy. In addition, penguins (Groscolas and Robin 2001) and bats (Yacoe 1983) put on extra muscle mass before migration or fasting, which is later catabolized as a nutritional reserve without apparent compromise of function. This skeletal muscle protein reserve may be augmented by the catabolism of smooth muscle, organ tissues, or extracellular matrix such as collagen (Cherel et al. 1994; Hissa et al. 1998). By utilizing small amounts of protein from some specific skeletal muscles while completely conserving protein in others and at the same time utilizing alternate potentially labile protein reserves, the denned bear is able to meet metabolic demands without severely compromising strength during extended fasting and limited mobility.

This study strongly supports our claim that bears exhibit limited atrophy with marginal strength loss compared to standard disuse models, but how do they compare to small hibernating and estivating animals? Overwintering golden-mantled ground squirrels (Spermophilus lateralis) exhibit a 15\%-20\% 


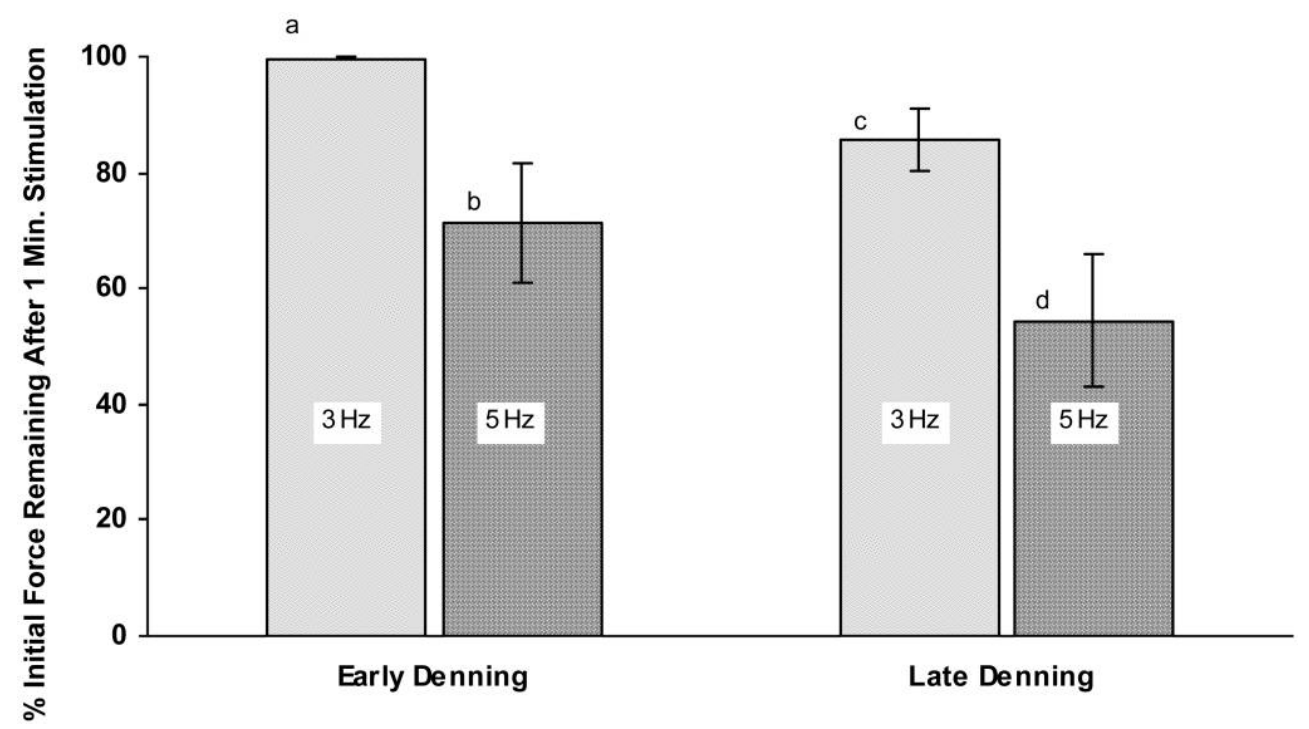

Figure 4. Muscle fatigue index measured in vivo. Vertical bars show percentage of strength remaining after 1 min of 3-Hz (light bars) and 5$\mathrm{Hz}$ (dark bars) stimulation during early (left bars) and late (right bars) denning. Different letters indicate values that are significantly different $(P<0.05)$ between early and late denning. Vertical lines represent \pm 1 SEM.

drop in wet weight of the soleus and extensor digitorum longus (EDL; Musacchia et al. 1989; Steffen et al. 1991, Wickler et al. 1991 ), with a $20 \%$ reduction in muscle protein and $30 \%$ decrease in muscle fiber cross-sectional area (Steffen et al. 1991). The white-tailed prairie dog (Cynomys leucurus) and blacktailed prairie dog (Cynomys ludovicianus) show a slightly lower loss in EDL muscle wet weight $(10 \%-15 \%)$ and reduction in protein content $(14 \%-17 \%)$ with no loss in cross-sectional area, culminating in an overall $22 \%-25 \%$ strength loss over the winter (Cotton 2005). In comparison, the hibernating black bear exhibited no loss in fiber cross-sectional area of the biceps femoris or gastrocnemius, no reduction in protein content of the gastrocnemius or vastus lateralis, and a drop of only about $10 \%$ in the protein content of the biceps femoris (Tinker et al. 1998; Lohuis et al. 2007). A similar conservation of muscle protein and size in the tibialis anterior may account for its marginal (23\%-29\%) strength loss in bears that is similar in magnitude to that of small-mammal hibernators (Cotton 2005).

It is noteworthy that estivating amphibians, such as the green-striped burrowing frog (Cyclorana alaboguttata), show no loss in wet weight of several hindlimb muscles or in contractile properties of the gastrocnemius (Hudson and Franklin $2002 a, 2002 b$ ). In addition, the isovelocity power output of aquatic Rana tempararia was unaltered during hibernation (West et al. 2006). However, ectotherms generally have a metabolic rate five to seven times lower than that of mammals (Else and Hulbert 1985; Brand et al. 1991) and may also be protected from muscle atrophy, in part because of very low body temperatures during cold winters (Hudson and Franklin $2002 a)$.

\section{Muscle Fatigue}

Equally important to mobility is the retention of protein within the sarcoplasmic reticulum for calcium release and uptake (Schulte et al. 1993; reviewed in Allen and Westerblad 2001). In addition, loss of vascular smooth muscle and changes in myoglobin content and enzyme activity are also associated with changes in muscle fiber function. We indirectly assessed these changes by measuring not only contractile force but also muscle fatigue and contractile kinetic properties.

Muscle fatigue is a result of repeated use or stimulation of muscle (Westerblad et al. 2000) without sufficient recovery interval and is characterized by a decrease in force output over time (reviewed in Allen and Westerblad 2001; Adams et al. 2003). Fatigue results from decreased oxygen delivery (McDonald et al. 1992), limited ATP availability, or reduced calcium release from sarcoplasmic stores (Allen et al. 1995; Favero 1999). Muscles that show a reduced oxidative capacity or loss of slow-oxidative fibers as a result of atrophy will fatigue more rapidly (Booth 1977; Fell et al. 1985; Witzmann et al. 1992).

Black bears appeared to sustain only a moderate loss of fatigue resistance over the winter. At the end of $110 \mathrm{~d}$ of fasting and confinement, bears still exhibited a profile of $29 \%$ and $44 \%$ decrease in force with $1 \mathrm{~min}$ of $3-\mathrm{Hz}$ and $5-\mathrm{Hz}$ stimulus, respectively. This increased susceptibility to fatigue measured in late winter is not one that should severely limit locomotor 


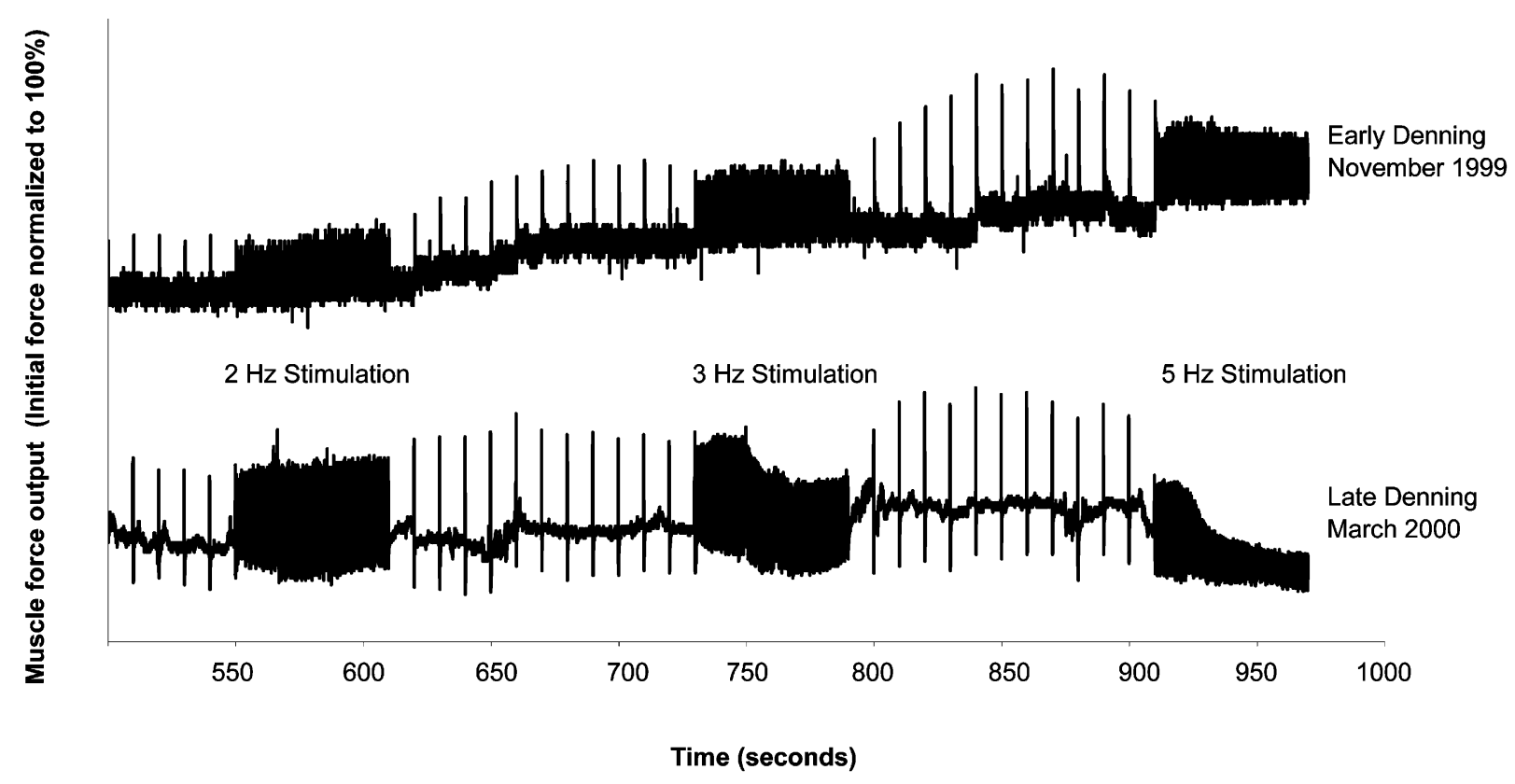

Figure 5. Representative early- and late-denning fatigue profiles from ankle dorsiflexors of bear 804 . Note that figure shows response only to 2-, 3-, and $5-\mathrm{Hz}$ stimuli because $0.5-\mathrm{Hz}$ and $1.0-\mathrm{Hz}$ stimulation did not produce a measurable fatigue response. Timescale of horizontal axis is adjusted accordingly. Spikes in force output every $10 \mathrm{~s}$ were muscle contractions generated by a single stimulus as part of the experimental protocol. These contractions were designed to ensure consistency throughout and between the measurement periods.

performance. For example, measures of fatigue in the tibialis anterior of healthy, fed, active human subjects tested with a stimulus protocol identical to that used in this study exhibit approximately a $25 \%$ and $50 \%$ reduction in force production in response to $1 \mathrm{~min}$ of $3-\mathrm{Hz}$ and $5-\mathrm{Hz}$ stimulation, respectively (Schulte-Mattler et al. 2003). After $110 \mathrm{~d}$ of fasting and limited mobility imposed by denning, bears still exhibited a fatigue profile similar to that of healthy, active, fed humans.

\section{In Vivo Assessment of Muscle Contractile Properties}

Mammalian skeletal muscle is a heterogeneous composition of slow-twitch type I and fast-twitch type II fibers with contractile properties that differ in part because of their MHC expression. Slow-twitch muscles contain mostly the MHC I slow isoform and some MHC IIa, which is the slowest of the fast MHCs. Fast-twitch muscles contain more MHC IIx and MHC IIb fast isoforms (reviewed in Baldwin and Haddad 2001; Caiozzo 2002). Unloading or immobilization causes atrophy as well as an increase in the proportion of fast relative to slow $\mathrm{MHC}$ isoforms, measured at both the single-fiber and whole-muscle levels (Caiozzo et al. 1998; reviewed in Baldwin and Haddad 2001; Caiozzo 2002). A notable type I to type II transition is evident in spaceflight (Caiozzo et al. 1996), and hindlimb suspension (Thomason et al. 1987; reviewed in Baldwin and Haddad 2001), with up to an $80 \%$ decrease in MHC I in slowtwitch muscles after $15 \mathrm{~d}$ of spinal isolation (Haddad et al.
2003). The MHC isoform composition of a muscle influences contraction velocity. A greater number of fibers in a muscle expressing type II fast MHC isoforms as a result of unloading would potentially result in increased whole-muscle contraction velocities and a tendency for that muscle to exhibit more fastglycolytic characteristics and less resistance to fatigue (Diffee et al. 1991; reviewed in Caiozzo 2002). In addition, relaxation kinetics are altered by unloading as sarcoplasmic reticulum calcium uptake is increased, leading to faster relaxation times (Schulte et al. 1993; Caiozzo et al. 1998). It is possible that changes in either of these parameters would result in a muscle that was functionally more fast-twitch with increased susceptibility to fatigue. However, none of the seven whole-muscle contractile properties measured in our study on bears-contraction time, half-maximal value time, half-maximum duration, time to peak force development and decay, and rate of force development and decay-were altered in response to anorexia and confinement imposed by $110 \mathrm{~d}$ of denning in bears (Table 1).

We did not directly test MHC isoform expression in this study of the tibialis anterior during early and late hibernation. However, in a study of overwintering bears in the same region, there was either no reduction or an increase in the MHC I slow isoform expression in the biceps femoris and gastrocnemius muscles (Rourke et al. 2006). This may be more typical than atypical of hibernators. Recent studies suggest that the mRNA (Rourke et al. 2004a) and expression of the MHC I slow isoform 
was retained in hibernating ground squirrels (Rourke et al. $2004 b$ ) and even modestly increased in prairie dogs (Rourke et al. 2006). It is certainly noteworthy that muscle function at the level of contractile properties was preserved in the tibialis anterior of bears in our study. These data are consistent with previous morphological studies (Tinker et al. 1998) that show either no change or marginal alteration in skeletal muscle fiber type ratios or MHC isoform expression (Rourke et al. 2006) of specific muscles in hibernating bears. Therefore, the moderate increase in susceptibility to fatigue observed in the tibialis anterior of our bears during late hibernation could have been due to a combination of factors, such as loss of myofibrillar and sarcoplasmic protein, impaired calcium release, decreased ATP availability, or reduced vascularization and associated oxygen delivery, in concert with an impaired oxidative capacity of this muscle. Any or all of these processes could result in altered contractile properties, contraction strength, or resistance to fatigue (reviewed in Allen and Westerblad 2001).

\section{Conclusions}

Bears in this study exhibited remarkable conservation of muscle function assessed by in vivo measurements of strength, fatigue, and contractile properties of the tibialis anterior over $110 \mathrm{~d}$ of denning. How is this possible? Bears rely heavily on fat as an energy source during hibernation (Nelson et al. 1973; Harlow et al. 2002). They are also capable of extremely efficient nitrogen sparing during winter; they are known to recycle almost $100 \% \rightarrow$ of the urea produced from protein catabolism (Barboza et al. 1997), which may be used to resynthesize lost skeletal muscle (Nelson et al. 1973). Furthermore, conservation of some muscle groups may occur preferentially over that of others. For example, while the gastrocnemius (Tinker et al. 1998) and vastus lateralis (Lohuis et al. 2007) of bears exhibit no loss of protein over the winter, the tibialis anterior (this study) and bicep femoris (Tinker et al. 1998) do exhibit a modest reduction, at a level well below that predicted for other animals experiencing disuse or fasting-induced atrophy. Nonmyofibrillar protein reserves may be used, which would spare structural skeletal muscle properties. These sources may include plasma protein, extracellular matrix, and smooth muscle or organ tissue. Rourkt $\rightarrow$ et al. (2006) indicate that small-mammal hibernators may retain or even increase MHC I slow isoforms through heavy muscle contractions during arousal. We have reported that bears may undergo repeated isometric and shivering move $\rightarrow$ ments while in the den (Harlow et al. 2004). Relatively moderate movements are sufficient to limit muscle atrophy (Rittweger et al. 2005) and retain strength (Gogia et al. 1988) and may be employed by these hibernating bears in order to pre $\rightarrow$ serve muscle integrity (Harlow et al. 2004). In spite of a size difference of almost three orders of magnitude and a $30^{\circ} \mathrm{C}$ difference in torpor body temperature, the black bear may conserve muscle function at least to the extent of or perhaps better than small-mammal hibernators. A distinct benefit would be achieved by the bears' uncompromised capacity of protein and strength retention of locomotor muscles in responding to threat or disturbance during winter dormancy or in foraging upon emergence from the den in the spring.

\section{Acknowledgments}

This research was supported by National Science Foundation grant IBN-9808785 to H.J.H. We thank the Colorado Division of Wildlife and the Wyoming Game and Fish Department for their cooperation and logistical support during this study. This project could not have been successful without technicians Mike Hooker, Craig Jamison, Joe Koloski, and Lyle Willmarth. We would also like to thank the many volunteers, especially Kevin McDonough, Mark Murphy, John Perdue, and Todd Perdue, who, along with many others, provided excellent assistance with bear tracking and den locating, often in snowy, subzero conditions. Many thanks to Gary Williams for his computer programming assistance and expertise.

\section{Literature Cited}

Adams G.R., V.J. Caiozzo, and K.M. Baldwin. 2003. Skeletal muscle unweighting: spaceflight and ground-based models. J Appl Physiol 95:2185-2201.

Alkner B.A. and P.A. Tesch. 2004. Knee extensor and plantar flexor muscle size and function following 90 days of bed rest with or without resistance exercise. Eur J Appl Physiol 93: 294-305.

Allen D.G., J. Lannergren, and H. Westerblad. 1995. Muscle cell function during prolonged activity: cellular mechanisms of fatigue. Exp Physiol 80:497-527.

Allen D.G. and H. Westerblad. 2001. Role of phosphate and calcium stores in muscle fatigue. J Physiol 536:657-665.

Andersen J.L., T. Gruschy-Knudsen, C. Sandri, L. Larsson, and S. Schiaffino. 1999. Bed rest increases the amount of mismatched fibers in human skeletal muscle. J Appl Physiol 86: 455-460.

Baldwin K.M. and F. Haddad. 2001. Plasticity in skeletal, cardiac, and smooth muscle. Invited review: effects of different activity and inactivity paradigms on myosin heavy chain gene expression in striated muscle. J Appl Physiol 90:345-357.

$\rightarrow$ Barboza P.S., S.D. Farley, and C.T. Robbins. 1997. Whole-body urea cycling and protein turnover during hyperphagia and dormancy in growing bears (Ursus americanus and U. arctos). Can J Zool 75:2129-2136.

$\rightarrow$ Barnes B.M. 1989. Freeze avoidance in a mammal: body temperatures below $0^{\circ} \mathrm{C}$ in an arctic hibernator. Science 244: 1593-1595.

Beck T.D.I. 1991. Black bears of west-central Colorado. Colo Div Wildl Tech Publ 39. 
$\rightarrow$ Berg H.E., G.A. Dudley, T. Haggmark, H. Ohlsen, and P.A. Tesch. 1991. Effects of lower limb unloading on skeletal muscle mass and function in man. J Appl Physiol 70:1882-1885.

$\rightarrow$ Berg H.E., L. Larsson, and P.A. Tesch. 1997. Lower limb skeletal muscle function after 6 wk of bed rest. J Appl Physiol 82: 182-188.

$\rightarrow$ Bintz G.L., D.L. Palmer, W.W. Mackin, and F.Y. Blanton. 1979. Selective tissue catabolism and water balance during starvation in Richardson's ground squirrels. Comp Biochem Physiol A 64:399-403.

Booth F.W. 1977. Time course of muscular atrophy during immobilization of hindlimbs in rats. J Appl Physiol 43:656-661.

$\rightarrow$ Boyer B.B. and B.M. Barnes. 1999. Molecular and metabolic aspects of mammalian hibernation. BioScience 49:713-724.

Brand M.D., P. Couter, P.L. Else, K.W. Withers, and A.J. Hulbert. 1991. Evolution of energy metabolism: proton permeability of the inner membrane of liver mitochondria is greater in a mammal than in a reptile. Biochem J 275:81-86.

$\rightarrow$ Brass T.J., M.K. Loushin, J. Day, and P.A. Iaizzo. 1996. An improved method for muscle force assessment in neuromuscular disease. J Med Eng Technol 20:67-74.

Buller A.J., C.J.C. Kean, K.W. Ranatunga, and J.M. Smith. 1984. Temperature dependence of isometric contractions of cat fast and slow skeletal muscles. J Physiol 35:25-31.

$\rightarrow$ Burlington R.F. and G.F. Klain. 1967. Gluconeogenesis during hibernation and arousal from hibernation. Comp Biochem Physiol 22:701-708.

$\rightarrow$ Caiozzo V.J. 2002. Plasticity of skeletal muscle phenotype: mechanical consequences. Muscle Nerve 26:740-768.

Caiozzo V.J., M.J. Baker, and K.M. Baldwin. 1998. Novel transitions in myosin isoforms: separate and combined effects of thyroid hormone and mechanical unloading. J Appl Physiol 85:2237-2248.

Caiozzo V.J., F. Haddad, M.J. Baker, R.E. Herrick, N. Prietto, and K.M. Baldwin. 1996. Microgravity-induced transformations of myosin isoforms and contractile properties of skeletal muscle. J Appl Physiol 81:123-132.

$\rightarrow$ Cherel Y., J. Gilles, Y. Handrich, and Y. LeMaho. 1994. Nutrient reserve dynamics and energetics during long term fasting in the king penguin (Aptenodytes patagonicus). J Zool (Lond) 234:1-12.

Cotton C.J. 2005. Protein Conservation and Temperature Tolerances of Tissue from Spontaneous and Facultative Hibernators: The White-Tailed Prairie Dog and Black-Tailed Prai rie Dog. MS thesis. University of Wyoming, Laramie.

De Ruiter C.J. and A. De Haan. 2000. Temperature effect on the force/velocity relationship of the fresh and fatigued human adductor pollicis muscle. Eur J Physiol 440:163-170. $\rightarrow$

Desplanches D., M.H. Mayet, B. Sempore, and R. Flandrois. 1987. Structural and functional responses to hindlimb suspension in rat muscle. J Appl Physiol 63:558-563.

Diffee G.M., V.J. Caiozzo, R.E. Herrick, and K.M. Baldwin $\rightarrow$ 1991. Contractile and biochemical properties of rat soleus and plantaris after hindlimb suspension. Am J Physiol 260: C528-C534.

Dudley G.A., P.D. Gollnick, V.A. Covertino, and P. Buchanan. 1989. Changes of muscle function and size with bed rest. Physiologist 32:S65-S66.

Edgerton V.R., M.Y. Zhou, Y. Ohira, H. Klitgaard, B. Jinag, G. Bell, B. Harris, B. Saltin, P.D. Gollnick, and R. Roy. 1995. Human fiber size and enzyme properties after 5 and 11 days of spaceflight. J Appl Physiol 78:1733-1739.

$\rightarrow$ Else P.L. and A.J. Hulbert. 1985. An allometric comparison of the mitochondria of mammalian and reptilian tissue: the implications for the evolution of endothermy. J Comp Physiol B 156:3-11.

Favero T.G. 1999. Sarcoplasmic reticulum $\mathrm{Ca}^{2+}$ release and muscle fatigue. J Appl Physiol 87:471-483.

Fell R.D., J.M. Steffen, and X.J. Musacchia. 1985. Effect of hypokinesia-hypodynamia on rat muscle oxidative capacity and glucose uptake. Am J Physiol 249:R308-R312.

Ferretti G., H.E. Berg, A.E. Minetti, C. Moia, S. Rampichini, and M. Narici. 2001. Maximal instantaneous power after prolonged bed rest in humans. J Appl Physiol 90:431-435.

Fitts R.H., D.R. Riley, and J.J. Widrick. 2000. Microgravity and skeletal muscle. J Appl Physiol 89:823-839.

2001. Functional and structural adaptations of skeletal muscle to microgravity. J Exp Biol 204:3201-3208.

Galster W.A. and P.R. Morrison. 1975. Gluconeogenesis in arctic ground squirrels between periods of hibernation. Am J Physiol 228:325-350.

$\rightarrow$ Gamrin L., H.E. Berg, P. Essen, P.A. Tesch, E. Hultman, P.J. Garlick, M.A. McNurlan, and J. Wernerman. 1998. The effect of unloading on protein synthesis in human skeletal muscle. Acta Physiol Scand 163:369-377.

Gogia P.P., V.S. Scheider, A.D. LeBlanc, J. Krebs, C. Kasson, and C. Pientok. 1988. Bed rest effect on extremity torque in healthy men. Arch Phys Med Rehabil 69:1030-1032.

Greenleaf J.E., R. Bulbulian, E.M. Bernauer, W.L. Haskell, and T. Moore. 1989. Exercise training protocols for astronauts in microgravity. J Appl Physiol 67:2191-2204.

Groscolas R. and J.-P. Robin. 2001. Long-term fasting and refeeding in penguins. Comp Biochem Physiol A 128:645-655.

Haddad F.R., R. Roy, H. Zhong, V.R. Edgerton, and K.M. Baldwin. 2003. Atrophy responses to muscle inactivity. I. Cellular markers of protein deficits. J Appl Physiol 95:781-790.

$\rightarrow$ Haida N., W.M. Fowler Jr., R.T. Abresch, D.B. Larson, R.B. Sharman, R.G. Taylor, and R.K. Entriken. 1989. Effect of hind-limb suspension on young and adult skeletal muscle. 1. Normal mice. Exp Neurol 103:68-76.

Harlow H.J., T. Lohuis, R.C. Anderson-Sprecher, and T.D.I. Beck. 2004. Body surface temperature profiles of hibernating black bears may be related to periodic muscle activity. J Mammal 85:414-419.

Harlow H.J., T.D. Lohuis, T.D.I. Beck, and P.A. Iaizzo. 2001. Muscle strength in overwintering bears. Nature 409:997. 
$\rightarrow$ Harlow H.J., T.D. Lohuis, R. Grogan, and T.D.I. Beck. 2002. Body mass and lipid changes by hibernating reproductive and non-reproductive black bears (Ursus americanus). Mammal 83:1020-1025.

$\rightarrow$ Harlow H.J. and G.E. Menkens. 1985. A comparison of hibernation in the black-tailed prairie dog, white-tailed prairie dog, and Wyoming ground squirrel. Can J Zool 64:793-796.

$\rightarrow$ Hilber K., Y.-B. Sung, and M. Irving. 2001. Effects of sarcomere length and temperature on the rate of ATP utilization by rabbit psoas muscle fibers. J Physiol (Lond) 531:771-780.

Hissa R., M. Puukka, E. Hohtola, M.-L. Sassi, and J. Risteli. 1998. Seasonal changes in plasma nitrogenous compounds of the European brown bear (Ursus arctos arctos). Ann Zool Fenn 35:205-213.

$\rightarrow$ Hortobagyi T., L. Dempsey, D. Fraser, D. Zheng, G. Hamilton, J. Lambert, and L. Dohm. 2000. Changes in muscle strength, muscle fibre size, and myofibrillar gene expression after immobilization and retraining in humans. J Physiol 524:293303.

$\rightarrow$ Hudson N.J. and C.E. Franklin. 2002a. Effect of aestivation on muscle characteristics and locomotor performance in the green-striped burrowing frog, Cyclorana alboguttata. J Comp Physiol B 172:177-182.

- 2002b. Maintaining muscle mass during extended disuse: aestivating frogs as a model species. J Exp Biol 205: 2297-2303.

Hudson N.J., S.A. Lehnert, A.A. Ingrahm, B. Symonds, C.E. Franklin, and G.S. Harper. 2006. Lessons from an estivating frog: sparing muscle protein despite starvation and disuse. Am J Physiol 290:R836-R843.

$\rightarrow$ Iaizzo P.A. and R.E. Poppele. 1990. Twitch relaxation of the cat soleus muscle at different lengths and temperatures. Muscle Nerve 13:1105-1112.

$\rightarrow$ Knapik J.J., B.H. Jones, C. Meredith, and W.J. Evans. 1987. Influence of a 3.5 day fast on physical performance. Eur J Appl Physiol Occup Physiol 56:428-432.

Koebel D.A., P.G. Miers, R.A. Nelson, and J.M. Steffen. 1991. Biochemical changes in skeletal muscle of denning bears ( $U r$ sus americanus). Comp Biochem Physiol B 100:377-380.

$\rightarrow$ Koerts-DeLang E., A.M.W.J. Schols, E.F.M. Wouters, G. GayanRamirez, and M. Decramer. 1998. Contractile properties and histochemical characteristics of the rat diaphragm after prolonged triamcinolone treatment and nutritional deprivation. J Muscle Res Cell Motil 19:549-555.

Koryak Y.A. 1998. Influence of 120-day 6 degrees head-down tilt bed rest on the functional properties of the neuromuscular system in man. Aviat Space Environ Med 69:766-770.

$\rightarrow$ Krawiec B.J., R.A. Frost, T.C. Vary, L.S. Jefferson, and C.H. Lang. 2005. Hindlimb casting decreases muscle mass in par $\rightarrow$ by proteosome-dependent proteolysis but independent of protein synthesis. Am J Physiol 289:E969-E980.

Lambertz D., C. Perot, R. Kaspranski, and F. Goubel. 2000.
Effects of long-term spaceflight on mechanical properties of muscles in humans. J Appl Physiol 90:179-188.

Larsson L., X. Li, H.E. Berg, and W.R. Frontera. 1996. Effects of removal of weight bearing function on contractility and myosin isoforms composition in single human muscle cells. Eur J Physiol 432:320-328.

Layne J.R., Jr., and M.E. Rice. 2003. Postfreeze locomotion performance in wood frogs (Rana sylvatica) and spring peepers (Pseudacris crucifer). Can J Zool 81:2061-2065.

LeBlanc A., C. Lin, L. Shackelford, V. Sinitsyn, H. Evans, O. Belichenko, B. Schenkman, et al. 2000. Muscle volume, MRI relaxation times (T2) and body composition after spaceflight. J Appl Physiol 89:2158-2164.

LeBlanc A.D., V.S. Schneider, H.J. Evans, C. Pientok, R. Rowe, and E. Spector. 1992. Regional changes in muscle mass following 17 weeks of bed rest. J Appl Physiol 73:2172-2178.

Lecker S.H. and A.L. Goldberg. 2002. Slowing muscle atrophy: putting the brakes on protein breakdown. J Physiol (Lond) 545:729.

Lecker S.H., V. Solomon, W.E. Mitch, and A.L. Goldberg. 1999. Muscle protein breakdown and the critical role of the ubiquitin-proteosome pathway in normal and disease states. J Nutr 129:227S-237S.

LeMaho Y., H.V. van Kha, H. Koubi, G. Dewasmes, J. Girard, P. Ferre, and M. Cagnard. 1981. Body composition, energy expenditure, and plasma metabolites in long term fasting geese. Am J Physiol 241:1059-1062.

Li J.B. and A.L. Goldberg. 1976. Effects of food deprivation on protein synthesis and degradation in rat skeletal muscles. Am J Physiol 231:441-448.

Lohuis T.D. 2002. Skeletal Muscle Protein Metabolism and Strength Retention in Active and Hibernating Free-Ranging Black Bears (Ursus americanus). PhD diss. University of $\mathrm{Wy}-$ oming, Laramie.

Lohuis T.D., H.J. Harlow, and T.D.I. Beck. 2007. Hibernating black bears (Ursus americanus) are in skeletal muscle protein balance over 110 days of winter anorexia and inactivity. Comp Biochem Physiol B (forthcoming), doi:10.1016/j.cbpb.2006.12.020.

McDonald K.S., M.D. Delp, and R.H. Fitts. 1992. Fatigability and blood flow in the rat gastrocnemius-soleus after hindlimb suspension. J Appl Physiol 73:1135-1140.

Musacchia X.J., J.M. Steffen, M.C. Steffen, T.E. Geoghegan, J.M. Dombrowski, W.K. Milsom, and R.F. Burlington. 1989. Morphometric and biochemical adaptations of skeletal muscle in hibernating and non-hibernating ground squirrels, Spermophilus lateralis. Pp. 217-224 in A. Malan and B. Canguilhem, eds. Living in the Cold: Second International Symposium. Institut National de la Sante et de la Recherche Medicale. Libbey Eurotext, Paris.

Narici M.V., B. Kayser, P. Darattini, and P. Cerretelli. 1997. Changes in electrically evoked skeletal muscle contractions during 17-day spaceflight and bed rest. Int J Sports Med 18: S290-S292. 
$\rightarrow$ Nelson R.A., G.E. Folk Jr., E.W. Pfeifer, J.J. Craighead, C.J $\rightarrow$ Jonkel, and D.L Steiger. 1983. Behavior, biochemistry, and hibernation in black, grizzly, and polar bears. Int Conf Bear Res Manag 5:284-290.

Nelson R.A., H.W. Wahner, D.B. McGill, and C.F. Code. 1973. Metabolism of bears before, during, and after winter sleep. Am J Physiol 224:491-496.

$\rightarrow$ Ploutz-Snyder L.L., P.A. Tesch, B. Hather, and G.A. Dudley. 1996. Vulnerability to dysfunction and muscle injury afte: $\rightarrow$ unloading. Arch Phys Med Rehabil 77:773-777.

$\rightarrow$ Reid M.B., G.J. Grubweiser, D.S. Stokic, S.M. Koch, and A.A. Leis. 1993. Development and reversal of fatigue in human tibialis anterior. Muscle Nerve 16:1239-1245.

$\rightarrow$ Reid W.D., A. Ng, and W.K. Milsom. 1995. Characteristics o $\rightarrow$ T diaphragm muscle fiber types in hibernating squirrels. Respir Physiol 101:301-309.

$\rightarrow$ Rittweger J., H.M. Frost, H. Schiessel, H. Ohshima, B. Alkner $\rightarrow$ P. Tesch, and D. Felsenberg. 2005. Muscle atrophy and bone loss after 90 days' bed rest and the effects of flywheel exercise and pamidronate. Bone 36:1019-1029.

$\rightarrow$ Rourke B.C., C.J. Cotton, H.J. Harlow, and V.J. Caiozzo. 2006. Maintenance of slow type I myosin protein and mRNA expression in overwintering prairie dogs (Cynomys leucurus and ludovicianus) and black bears (Ursus americanus). J Comf $\rightarrow$ Physiol B 176:709-720.

$\rightarrow$ Rourke B.C., A. Qin, F. Haddad, K.M. Baldwin, and V.P. Caiozzo. 2004a. Cloning and sequencing of myosin heav $\rightarrow$ chain isoform cDNAs in golden-mantled ground squirrels: effects of hibernation on mRNA expression. J Appl Physiol 97:1985-1991.

$\rightarrow$ Rourke B.C., Y. Yokoyama, W.K. Milsom, and V.J. Caiozzo. 2004b. Myosin isoform expression and MAFbx mRNA levels in hibernating golden-mantled ground squirrels (Spermophilus lateralis). Physiol Biochem Zool 77:582-595.

$\rightarrow$ Roy R.R., H. Zhong, R.J. Monti, K.A. Vallance, and V.R. Edgerton. 2002. Mechanical properties of the electrical silent adult rat soleus muscle. Muscle Nerve 26:404-412.

Schulte L.M., J. Navarro, and S.C. Kandarian. 1993. Regulation of sarcoplasmic reticulum calcium pump gene expression by hindlimb unweighting. Am J Physiol 264:C1308-C1315.

$\rightarrow$ Schulte-Mattler W.J., T. Muller, M. Deschauer, F.N. Gellerich, P.A. Iaizzo, and S. Zierz. 2003. Increased metabolic muscle fatigue is caused by some but not all mitochondrial mutations. Arch Neurol 60:50-58.

$\rightarrow$ Steffen J.M., D.A. Koebel, X.J. Mussachia, and W.K. Milsom. 1991. Morphometric and metabolic indices of disuse in muscles of hibernating ground squirrels. Comp Biochem Physiol B 99:815-819.

Talmadge R.J., R.R. Roy, and V.R. Edgerton. 1995. Prominence of myosin heavy chain hybrid fibers in soleus muscle of spinal cord-transected rats. J Appl Physiol 78:1256-1265.

$\rightarrow \longrightarrow$. 1999. Persistence of hybrid fibers in rat soleus after spinal cord transaction. Anat Rec 255:188-201.
Tesch P.A., H.E. Berg, D. Bring, H.J. Evans, and A.D. LeBlanc. 2004. Effects of 17-day spaceflight on knee-extensor muscle function and size. Eur J Appl Physiol 93:463-468.

$\rightarrow$ Thom J.M., M.W. Thompson, P.A. Ruell, G.J. Bryant, J.S. Fonda, A.R. Harmer, X.A. DeJong, and S.K. Hunter. 2001. Effect of 10-day cast immobilization on sarcoplasmic reticulum calcium regulation in humans. Acta Physiol Scand 172: 141-147.

Thomason D.B. and F.W. Booth. 1990. Atrophy of the soleus muscle by hindlimb unweighting. J Appl Physiol 68:1-12.

Thomason D.B., R.E. Herrick, D. Surdyka, and K.M. Baldwin. 1987. Time course of soleus muscle myosin expression during hindlimb suspension and recovery. J Appl Physiol 63:130-137.

Tinker D.B., H.J. Harlow, and T.D.I. Beck. 1998. Protein use and muscle fiber changes in free ranging, hibernating black bears. Physiol Zool 71:414-424.

Wang G. and M. Kawai. 2001. Effect of temperature on elementary steps of the cross bridge cycle in rabbit soleus slowtwitch fibers. J Physiol (Lond) 531:219-234.

$\rightarrow$ West T.G., P.H. Donohoe, J.F. Staples, and G.N. Askew. 2006. Tribute to R.G. Boutilier: the role for skeletal muscle in the hypoxia-induced hypometabolic responses of submerged frogs. J Exp Biol 209:1159-1168.

$\rightarrow$ Westerblad H., J.D. Brunton, D.G. Allen, and J. Lannergren. 2000. Functional significance of $\mathrm{Ca}^{2+}$ in long-lasting fatigue of skeletal muscle. Eur J Appl Physiol 83:166-174.

Wickler S.J., B.A. Horowitz, and K.S. Klott. 1987. Muscle function in hibernating hamsters: a natural analog to bedrest? J Therm Biol 12:163-166.

Wickler S.J., D.F. Hoyt, and F. van Breukelen. 1991. Disuse atrophy in the hibernating golden-mantled ground squirrel, Spermophilus lateralis. Am J Physiol 261:R1214-R1217.

Widrick J.J., K.M. Norenberg, J.G. Romatowski, C.A. Blaser, M. Karnahek, J. Sherwood, S.W. Trappe, T.A. Trappe, D.L. Costill, and R.H. Fitts. 1998. Force velocity-power and force pCa relationships of human soleus fibers after 17 days of bedrest. J Appl Physiol 85:1949-1956.

Witzmann F.A., D.H. Kim, and R.H. Fitts. 1992. Recovery time course in contractile function of fast and slow skeletal muscle after hindlimb immobilization. J Appl Physiol 52:677-682.

Yacoe M.E. 1983. Protein metabolism in the pectoralis muscle and liver of hibernating bats, Eptesicus fuscus. J Comp Physiol 152:137-144.

$\rightarrow$ Zange J., K. Muller, M. Schuber, H. Wackerhage, U. Hoffman, R.W. Gunther, G. Adam, et al. 1997. Changes in muscle performance, energy metabolism, and muscle volume caused by long term stay on space station MIR. Int J Sports Med 18:S308-S309.

Zar J.H. 1999. Biostatistical Analysis. 4th ed. Prentice Hall, Upper Saddle River, NJ.

Zhan W.-Z. and G.C. Sieck. 1992. Adaptations of diaphragm and medial gastrocnemius muscles to inactivity. J Appl Physiol 72:1445-1543. 